\title{
Ética: agir e porvir
}

António Faria-Vaz*

"It appears that the theory and the practice of informed consent are out of joint in some crucial ways. This is particularly true for primary care settings, a context typically ignored by

medical ethics literature, but where the majority of doctor-patient encounters occur.»

Howard Brody

P ublicamos neste número uma recomendação elaborada pela Comissão de Ética para a Saúde da Administração Regional de Saúde do Norte sobre consentimento informado. Trata-se de um documento que procura debruçar-se circunstanciadamente sobre o processo de obtenção do consentimento informado em actos de diagnóstico e terapêutica e em estudos de investigação. $^{2}$

A publicação do documento-guia, para além da sua óbvia e inequívoca utilidade como instrumento de apoio e reflexão à nossa prática clínica é, antes de mais, um gesto de respeito e de imensa admiração que a revista e o seu corpo editorial querem prestar à Administração Regional de Saúde do Norte e aos membros e colegas da Comissão de Ética para a Saúde da ARS do Norte.

À ARS do Norte pela originalidade da sua iniciativa, ao conseguir ler e interpretar a necessidade de dispor de uma Comissão de Ética para a Saúde, sendo tanto mais significativa quanto se trata da primeira e única comissão ética de âmbito regional, orientada para os Cuidados de Saúde Primários. Com esta iniciativa é possível dispor de um espaço de diálogo, de reflexão e bioética que promove e zela para que a investigação e a prestação de cuidados de saúde se rejam por elevados padrões éticos, garantindo a protecção da dignidade humana e respeitando a autonomia dos utentes do Serviço Nacional de Saúde. ${ }^{3}$

Aos colegas e membros da Comissão de Ética do Norte devemos reconhecer a qualidade do seu trabalho, pioneiro de um agir ético que cumpre as características que lhe são próprias: independência, capacidade de

*Director da Revista Portuguesa de Clínica Geral reflexão não enviesada, respeito pela sua área de competência, respeito pelas pessoas, conhecimento dos princípios fundamentais da bioética ${ }^{4} \mathrm{e}$, não menos importante, a transparência da sua actuação.

O consentimento informado pode ser considerado como uma afirmação livre e esclarecida que um ser humano presta em relação a quaisquer actos médicos a serem praticados na sua pessoa. ${ }^{5}$

A melhor forma de exprimir e definir consentimento informado seria através da análise global dos seus elementos constituintes. ${ }^{6}$ Segundo Beauchamp e Childress seriam, os componentes constituintes de um consentimento informado estariam divididos em três etapas. A primeira, designada como pré-condições, incluiria dois elementos, a competência (enquanto capacidade de compreender e decidir) e a voluntariedade (na decisão). A segunda, relativa aos componentes de informação, compreende a explicação (do material de informação), a recomendação (de um plano de tratamento) e a compreensão da informação e da recomendação proposta. A última etapa, decisão do consentimento, abrangeria a decisão (a favor do plano de tratamento) e a autorização (do plano escolhido). ${ }^{7}$

A obtenção do consentimento informado no contexto dos cuidados primários, é bom que se saliente, tem particularidades que interessará relevar. Em primeiro lugar, não se trata de aplicar de uma forma mecânica a prática de alguns hospitais que, nalguns casos, ainda que felizmente raros, transformaram essa obrigação ética num acto burocrático administrativo, a assinatura de um documento que pretensamente concede autorização para a realização de determinadas intervenções. O consentimento informado, no contexto da prática de um médico de família, constitui uma oportunidade renovada de promover a relação médico doente e a participação dos doentes no processo de decisão. Neste contexto, exige do profissional de saúde competências e aptidões de comunicação que lhe permitam habilitar os doentes com a informação adequada e apropriada, de modo a actuar como um agente activo, como um parceiro no processo terapêutico e no processo de saúde. Visto desta forma, poderíamos afir- 
mar que o processo de consentimento em cuidados primários não se centra na obtenção de uma autorização formal mas na capacidade de o incluir e integrar no processo normal de uma consulta, optimizando a participação dos doentes na exacta medida dos seus desejos.

Assim sendo, poderíamos considerar como Brody que o consentimento informado é um ingrediente essencial das boas práticas em Medicina Geral e Familiar e que, sem o seu cumprimento, não será possível promover e realizar um exercício clínico de qualidade.

\section{REERÊNCIAS}

1. Brody H. Transparency: Informed Consent in Primary Care. The Hastings Center Report 1989 Sep-Oct; 19 (5): 5-9.

2. Comissão de Ética para a Saúde da ARS Norte. Documento-Guia sobre Consentimento Informado. Rev Port Clin Geral 2009 Set-Out; 25 (5):524-8.
3. Almeida F. Comissões de Ética para a Saúde : suas naturezas e tarefas. In : Neves MC, coord. Comissões de Ética: das bases teóricas à actividade quotidiana. $2^{\mathrm{a}}$ ed. rev. Ponta Delgada: Centros de Estudos de Bioética / Pólo dos Açores; 2002. p. 152.

4. OsswaldW. Comissões de Ética: uma reflexão sobre a sua justificação. In : Neves MC, coord. Comissões de Ética: das bases teóricas à actividade quotidiana. $2^{\mathrm{a}}$ ed. rev. Ponta Delgada: Centros de Estudos de Bioética / Pólo dos Açores; 2002. p. 125.

5. Simões JA. O consentimento informado e o médico de família. Rev Port Clin Geral 2009 Set-Out; 25 (5):522-3.

6. Beauchamp TL, Faden RR. Meaning and elements of informed consent. In: Reich W, editor. Encyclopedia of Bioethics. New York: McMillan; 1995. p. 1238-41.

7. Beauchamp T, Childress J. Principles of Biomedical Ethics. 5th ed. Oxford: Oxford University Press; 2001. p. 58-9. 